\title{
Normal Skin
}

National Cancer Institute

\section{Source}

National Cancer Institute. Normal Skin. NCI Thesaurus. Code C74593.

The pores are visible but not large. The skin texture is neither fine or thick and it neither feels dry or oily to the touch. 